\section{Higher Prevalence of Metabolic Syndrome in Patients with Psoriatic Arthritis: A Comparison with a Control Group of Noninflammatory Rheumatologic Conditions}

\section{To the Editor:}

In our recent report, we showed that metabolic syndrome (MetS) is highly prevalent in patients with psoriatic arthritis (PsA) and is independently associated with the severity of underlying Ps ${ }^{1}$. This finding suggested that the higher burden of musculoskeletal inflammation may play a major role in the development of MetS. We acknowledge that one of the limitations of our study was the lack of a control group. Herein, we have recruited an age-, sex-, and race/ethnicity-matched control group attending rheumatology clinics with noninflammatory rheumatologic conditions. Our objective was to compare the prevalence of MetS in this control group with our earlier published cohort of patients with PsA to further test the inflammation-cardiovascular disease (CVD) hypothesis.

The control group consisted of 100 consecutive patients attending rheumatology clinics with noninflammatory conditions (osteoarthritis $=27$, fibromyalgia $=36$, regional musculoskeletal pain $=25$, osteoporosis $=12$ ). These patients were recruited from December 2014 through to March 2015. None of these patients had concomitant chronic inflammatory joint disease, and none of these patients were using corticosteroids or disease-modifying antirheumatic drugs. Similar to our earlier report, MetS was diagnosed as per the revised guidelines developed by the National Heart, Lung, and Blood Institute and the American Heart Association ${ }^{2}$. The demographics and clinical variables of the PsA cohort of 283 patients has already been described in our earlier publication ${ }^{1}$.

Table 1 provides a comparison of demographics and the components of MetS among these 2 groups. The prevalence of MetS is much higher in patients with PsA compared to a well-matched control group (44\% vs $29 \%$, $\mathrm{p}=0.009$ ). Among the components of MetS, increased waist circumference and hypertension were significantly more common among patients with PsA. Table 2 describes the association of demographics, MetS, and its different components with the diagnostic category of PsA or the control group on univariate analysis. Because of potential confounding effect, a body mass index-adjusted model was also used to assess associations of MetS with PsA and the controls using logistic regression. It shows clearly that MetS was significantly associated with PsA compared with the control population of predominantly noninflammatory rheumatic conditions.

There is considerable evidence from large observational cohorts, both

Table 1. Comparison of descriptive characteristics and metabolic syndrome components among patients with PsA and the patients with noninflammatory rheumatologic conditions. Values are \% unless otherwise specified.

\begin{tabular}{lcc}
\hline Characteristics & Patients with & Patients with \\
PsA, $n=283$ & Noninflammatory \\
& Rheumatologic \\
& Conditions, $n=100$
\end{tabular}

\begin{tabular}{lccc}
\hline Male & 47 & 46 & 0.81 \\
Age, yrs, mean \pm SD & $54.6 \pm 12$ & $53.7 \pm 14$ & 0.55 \\
$\begin{array}{l}\text { Disease duration, yrs, } \\
\text { mean } \pm \text { SD }\end{array}$ & $19.4 \pm 9$ & $10 \pm 4$ & $<0.001$ \\
MetS & 44 & 29 & $\mathbf{0 . 0 0 9}$ \\
BMI, mean \pm SD & $29 \pm 5$ & $27.7 \pm 2$ & $\mathbf{0 . 0 0 1}$ \\
Increased waist circumference & 55.8 & 41 & $\mathbf{0 . 0 1 1}$ \\
Hyperglycemia & 30 & 24 & 0.22 \\
Hypertriglyceridemia & 43.4 & 34 & 0.09 \\
Reduced HDL levels & 19 & 17 & 0.59 \\
Hypertension & 74 & 57 & $\mathbf{0 . 0 0 2}$ \\
\hline
\end{tabular}

Significant data are in bold face. PsA: psoriatic arthritis; MetS: metabolic syndrome; BMI: body mass index; HDL: high-density lipoprotein.
Table 2. Univariate and BMI-adjusted model describing associations of different clinical variables among patients with psoriatic arthritis $(n=283)$ and controls $(n=100)$.

\begin{tabular}{|c|c|c|c|c|c|c|}
\hline \multirow[t]{2}{*}{ Characteristics } & \multicolumn{3}{|c|}{ Univariate Model } & \multicolumn{3}{|c|}{ BMI-adjusted Model } \\
\hline & OR & $95 \% \mathrm{CI}$ & $\mathrm{p}$ & $\mathrm{OR}$ & $95 \% \mathrm{CI}$ & $\mathrm{p}$ \\
\hline Male & 1.05 & 066-1.66 & 0.81 & & & \\
\hline Age & 1.005 & $0.98-1.02$ & 0.55 & & & \\
\hline MetS & 1.90 & $1.16-3.12$ & 0.010 & 1.67 & $1.00-2.79$ & 0.04 \\
\hline BMI & 1.06 & $1.010-1.12$ & 0.017 & & & \\
\hline $\begin{array}{l}\text { Increased waist } \\
\text { circumference }\end{array}$ & 1.81 & $1.14-2.88$ & 0.011 & & & \\
\hline Hyperglycemia & 1.38 & $0.81-2.33$ & 0.22 & & & \\
\hline $\begin{array}{l}\text { Hypertriglyceri- } \\
\text { demia }\end{array}$ & 1.49 & $0.92-2.40$ & 0.09 & & & \\
\hline $\begin{array}{l}\text { Reduced HDL } \\
\text { levels }\end{array}$ & 1.17 & $0.64-2.14$ & 0.59 & & & \\
\hline Hypertension & 2.13 & $1.32-3.43$ & 0.002 & & & \\
\hline
\end{tabular}

BMI: body mass index; MetS: metabolic syndrome; HDL: high-density lipoprotein.

retrospective and prospective, and also by using different imaging techniques, demonstrating the association of PsA with heightened CV risk ${ }^{1,3}$. MetS is a cluster of 5 classic CV risk factors well-recognized for coronary artery diseases; as a group, MetS may confer a CV risk higher than the individual components. Further, it is interesting to note that the presence of MetS can influence PsA treatment efficacy. For example, a recent study has shown that MetS is associated with a lower probability (an inverse association on multivariate regression model, OR $0.56, \mathrm{p}<0.001$ ) of achieving minimal disease activity in patients with PsA receiving therapy with tumor necrosis factor inhibitors ${ }^{4}$.

There has been an increased recognition of the potential association of inflammation with CVD; for example, it has been postulated that inflammation leads to insulin resistance with resultant endothelial cell dysfunction and atherosclerosis, which eventually results in myocardial infarction and stroke when there is involvement of coronary, carotid, or cerebral arteries ${ }^{5}$. Similarly, it has been shown that MetS is associated with a state of chronic, low-grade inflammation ${ }^{6}$. Our pretest hypothesis was that there was a higher prevalence of MetS in PsA because of the coexistence of skin and musculoskeletal inflammation, and the resultant greater inflammatory load led to increased CVD. In this study, among patients without PsA, the prevalence of MetS was comparable to an estimated prevalence of MetS in the Western population of $15-24 \%^{7,8}$. There are now emerging data investigating the association of burden of inflammation in PsA with comorbidities ${ }^{9,10}$. For example, a recent study has shown that the cumulative inflammatory burden, as reflected by cumulative averages of repeated measures of erythrocyte sedimentation rate, was associated with increased arterial stiffness in patients with PsA, even after adjustment for CV risk factors, emphasizing the important involvement of chronic inflammation in accelerating the development of CVD in patients with PsA ${ }^{9}$.

The findings of our study are important and further support the hypothesis that the risk of MetS increases with the presence of systemic inflammatory condition. To our knowledge, our current report is the largest to date to have compared the prevalence of MetS among patients with PsA with a control group, and in conjunction with our earlier publication ${ }^{1}$, it further supports the inflammation-CVD hypothesis.

Our study confirms the high prevalence of MetS in patients with PsA compared with a control group well-matched for age, sex, and ethnicity, probably reflecting the increasing burden of inflammation. Because CVD is the leading cause of mortality in patients with PsA, regular screening and vigorous control of these metabolic and $\mathrm{CV}$ risk factors cannot be overemphasized. 
MUHAMMAD HAROON, MB, MMedSc, MRCPI, Division of Rheumatology, Department of Medicine, University Hospital Kerry, Tralee, and Department of Rheumatology, St. Vincent's University Hospital, Dublin, and Clinical Senior Lecturer, University College Cork, Cork; ADNAN BIN RAFIQ CHAUDHRY, MBBS, Division of Rheumatology, Department of Medicine, University Hospital Kerry; OLIVER FITZGERALD, MD, FRCPI, FRCP (UK), Department of Rheumatology, St. Vincent's University Hospital, Dublin, Ireland. Address correspondence to Dr. M. Haroon, Consultant Rheumatologist, Division of Rheumatology, Department of Medicine, University Hospital Kerry, Tralee, Ireland.

E-mail: mharoon301@hotmail.com

\section{REFERENCES}

1. Haroon M, Gallagher P, Heffernan E, FitzGerald O. High prevalence of metabolic syndrome and of insulin resistance in psoriatic arthritis is associated with the severity of underlying disease. J Rheumatol 2014;41:1357-65.

2. Grundy SM, Cleeman JI, Daniels SR, Donato KA, Eckel RH, Franklin BA, et al; American Heart Association; National Heart, Lung, and Blood Institute. Diagnosis and management of the metabolic syndrome: an American Heart Association/National Heart, Lung, and Blood Institute Scientific Statement. Circulation 2005;112:2735-52.

3. Tobin AM, Veale DJ, Fitzgerald O, Rogers S, Collins P, O'Shea D, et al. Cardiovascular disease and risk factors in patients with psoriasis and psoriatic arthritis. J Rheumatol 2010;37:1386-94.

4. Costa L, Caso F, Ramonda R, Del Puente A, Cantarini L, Darda
MA, et al. Metabolic syndrome and its relationship with the achievement of minimal disease activity state in psoriatic arthritis patients: an observational study. Immunol Res 2015;61:147-53.

5. Boehncke WH, Boehncke S, Tobin AM, Kirby B. The 'psoriatic march': a concept of how severe psoriasis may drive cardiovascular comorbidity. Exp Dermatol 2011;20:303-7.

6. Hotamisligil GS. Inflammation and metabolic disorders. Nature 2006;444:860-7.

7. Ford ES, Giles WH, Dietz WH. Prevalence of the metabolic syndrome among US adults: findings from the Third National Health and Nutrition Examination Survey. JAMA 2002;287:356-9.

8. Hu G, Qiao Q, Tuomilehto J, Balkau B, Borch-Johnsen K, Pyorala K; DECODE Study Group. Prevalence of the metabolic syndrome and its relation to all-cause and cardiovascular mortality in nondiabetic European men and women. Arch Intern Med 2004;164:1066-76.

9. Shen J, Shang Q, Li EK, Leung YY, Kun EW, Kwok LW, et al. Cumulative inflammatory burden is independently associated with increased arterial stiffness in patients with psoriatic arthritis: a prospective study. Arthritis Res Ther 2015;17:75.

10. Lin YC, Dalal D, Churton S, Brennan DM, Korman NJ, Kim ES, et al. Relationship between metabolic syndrome and carotid intima-media thickness: cross-sectional comparison between psoriasis and psoriatic arthritis. Arthritis Care Res 2014;66:97-103.

J Rheumatol 2016;43:2; doi:10.3899/jrheum.150757 